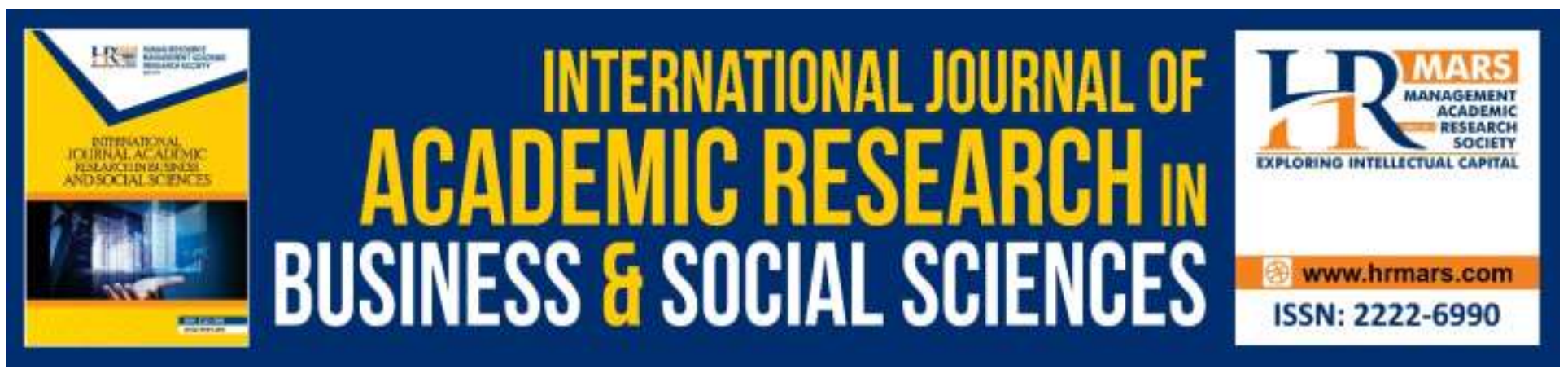

\title{
The Study on the Elderly People's Changes of Meaning in Life in the Intergenerational Program
}

\author{
Meng-Chieh Chao
}

To Link this Article: http://dx.doi.org/10.6007/IJARBSS/v10-i2/6940

DOI:10.6007/IJARBSS/v10-i2/6940

Received: 10 January 2020, Revised: 25 January 2020, Accepted: 09 February 2020

Published Online: 20 February 2020

In-Text Citation: (Chao, 2020)

To Cite this Article: Chao, M.-C. (2020). The Study on the Elderly People's Changes of Meaning in Life in the Intergenerational Program. International Journal of Academic Research in Business and Social Sciences, 10(2), 422-430.

Copyright: (C) 2020 The Author(s)

Published by Human Resource Management Academic Research Society (www.hrmars.com)

This article is published under the Creative Commons Attribution (CC BY 4.0) license. Anyone may reproduce, distribute, translate and create derivative works of this article (for both commercial and non-commercial purposes), subject to full attribution to the original publication and authors. The full terms of this license may be seen at: http://creativecommons.org/licences/by/4.0/legalcode

Vol. 10, No. 2, 2020, Pg. 422 - 430

http://hrmars.com/index.php/pages/detail/IJARBSS

JOURNAL HOMEPAGE

Full Terms \& Conditions of access and use can be found at http://hrmars.com/index.php/pages/detail/publication-ethics 


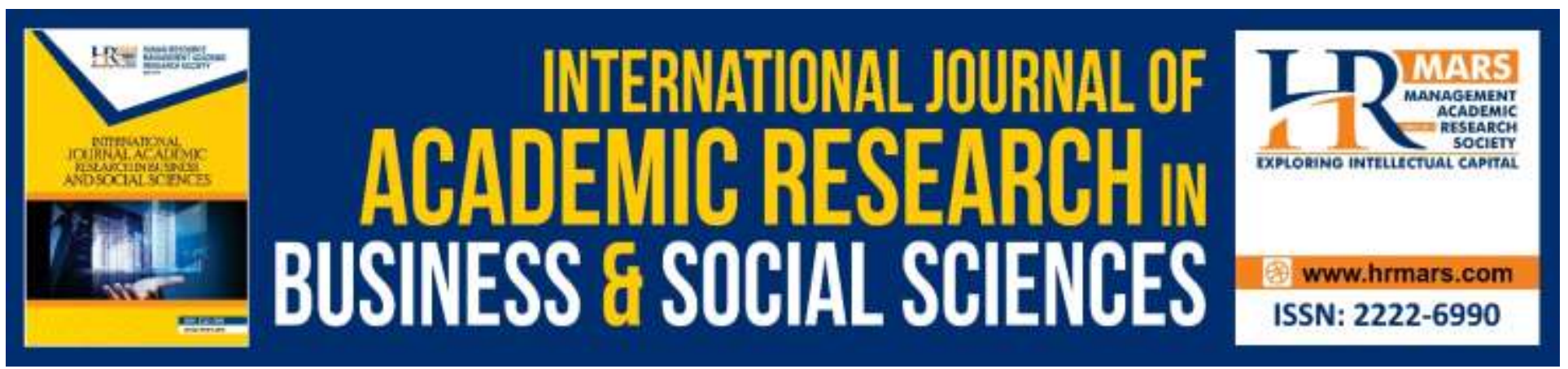

\title{
The Study on the Elderly People's Changes of Meaning in Life in the Intergenerational Program
}

\author{
Meng-Chieh Chao \\ Ching Kuo Institute of Management and Health/Department of Early Childhood Educare \\ Taiwan
}

\begin{abstract}
With elderly people as research objects, this study aimed to find out the influence on elderly people's meaning in life after they took part in intergenerational programs. Eight elderly people took part in this research project, attending intergenerational activities at a preschool once a week, eight weeks in total.
\end{abstract}

Elderly people were interviewed shortly after they completed the intergenerational program. Following facts were obtained from the interview: (1) Elderly people had improved their life meaning after they took part in intergenerational learning activities. (2) Upon completion of intergenerational program, elderly people exhibited significant improvement of life meaning in several aspects such as individual value, sense of direction and sense of fulfillment while less improvement of life meaning in their sense of autonomy.

Keywords: Intergenerational Program, Elderly, Meaning in life

\section{Introduction}

In Taiwan, the aged population increases steadily as time passes by. In 2018 , the aged population, 65and-older seniors, constituted $14.05 \%$ of total population. Since then, Taiwan has stepped into an aging society. Elderly people's wisdom and experiences are valuable. The younger generations can benefit from the elderly people's wisdom and experiences. In 1995, Ekstrom and Pei (1999) pointed out the elderly people's learning and participation method in recent years serves as a paradigm in which elderly people have turned from social dependents into resource providers, from social isolators into intergenerational connectors, and from ability-disadvantaged people into lifetime experience providers. For this reason, the learning model which stresses sharing and assistance among different generations - intergenerational programs - are meaningful for elderly people. Kaplan (2001) defined intergenerational programs as a meaningful and continuous program designed for resource-exchange and mutual learning between elderly people and younger generations, and with the intergenerational program, elderly people act as guilders for the younger generations in order to 
eliminate the stereotype between different generations and thereby encourages all generations to respect the difference among them. There is no doubt that intergenerational programs are a perfect learning method for elderly people to make best use of their skills and at the same time learn something new to them. Moreover, intergenerational programs allow elderly people to renew the meaning and purpose of life when they participate in the activities and interact with others, which are very important for their aging process Moore, Metcalf and Schow (2000). In this connection, how to help elderly people gain knowledge, identify the meaning in life, and improve their wisdom is an important task when we encourage elderly people to take part in the learning programs. This study started with the discussion on elderly people's participation in preschool's intergenerational program, and with the facts acquired from elderly people's teaching and guiding process, this study summarized the elderly people's life experience and thereby identified elderly people's meaning in life and the influence on them imposed by the intergenerational program.

\section{Literature Review}

Many researchers have extensively discussed the connotation of "meaning in life." According to Baum (1988), people identify and confirm their existence through the meaning in their life. Reker (1997) defined "meaning in life" as the direction, order and reasons of life, and with the meaning in life, people find out who they are and construct a strong social consciousness. With the "meaning in life", individuals know how to interpret and transform their experiences. But, how do elderly people identify the meaning in their life? Many elderly people lose their meaning in life after they retire (Reitzes and Mutran, 1994). For elderly people, the "meaning in life" comes from their relationship with others. They feel they are being needed whenever they have a chance to do something for their families and friends. They feel love, recognition and respect when they interact with their families and friends (Krause, 2007). Based on the facts stated above, elderly people construct their meaning in life when they interact with others. For the elderly people who are retired and have fewer chances to meet people, it is especially important to confirm the meaning in their life and the value of their life through participation in social activities and learning.

Hatton-Yeo and Ohsako (2000) introduced an intergenerational program for younger generations and elderly generation to exchange resources and learn from each other on a continual and purposeful basis. However, few researchers have focused on elderly people when they studied intergenerational programs. Up until today, most researchers focused on infants or children, in particular the study of the influence imposed by intergenerational programs. According to the study of elderly people, however, intergenerational programs have imposed positive influence on elderly people and improved the factors related to elderly people's meaning in life such as well-being and satisfaction with life. Mendis (1993) studied the psychological well-being of elderly people who took part in the intergenerational programs held by preschools for $3-4$ years old children. Eight weeks after elderly people were paired with children, elderly people exhibited significant difference in two aspects: (1) The social distance between elderly people and children decreased, and (2) Elderly people improved their self-esteem, control and satisfaction with life. According to Wenzel and Sorensen (2000), elderly people improved their social awareness after they took part in the intergenerational programs held in nursing homes. LinOu (2000) divided 15 elderly people into control group and experimental group. The elderly people of experimental group joined an intergenerational program in a preschool where 
INTERNATIONAL JOURNAL OF ACADEMIC RESEARCH IN BUSINESS AND SOCIAL SCIENCES Vol. 10, No. 2, Feb, 2020, E-ISSN: 2222-6990 @ 2020 HRMARS

they were paired with children. The research results confirmed the correlation among elderly people's mobility, perceived control and self-esteem. By taking part in intergenerational programs, elderly people have identified the positive meaning in their life which guides them to face their life and to improve the value of their life. Based on the discussions stated above, this study aimed to find out elderly people's changes of individual value, sense of direction, sense of autonomy and sense of fulfillment after they took part in intergenerational programs.

\section{Research Design and Implementation}

This study chose a Kindergarten in Taipei as the experiment site in which activities were arranged once a week, one hour each time, eight weeks in total. Researcher invited eight elderly people - six females and two males, age between 62 and 78, graduates of junior college or higher education institution - to participate in the intergenerational program. Each week the elderly people took turn lecturing 30 children at age 6 . Lectures were arranged in accordance with the elderly people's specialties such as karate, string figure and folklore stories. After giving lectures, elderly people remained in the classroom to chat and interact with children. In an effort to find out the influence on elderly people imposed by the intergenerational program, researcher discussed the meaning in life with the elderly people two weeks after the intergenerational program was completed.

\section{Research Results and Discussions}

I. The individual value sensed by elderly people after they took part in intergenerational program

1. Satisfied with their teaching performance

After taking part in the intergenerational program, elderly people understood they still had ability and experience to do something although they had retired.

I retired 11 years ago. I didn't have any chance to contact any child or any student in the past 11 years. I'm glad that I still had the passion to interact with 6 years old children. I felt pretty good, still young. I don't feel old at all. For me, it's really positive. This program is meaningful for us (B-1-15).

I was thinking...it's been a long time since I retired...20 years at least. If you want me to teach again, I will check what I learned before... I still know how to teach. I haven't totally forgotten what I learned before. I still can teach. All I have to do is to check the data again (B-1-15).

\section{Pleased with the children's positive feedback}

Each elderly person was responsible for one activity. In each and every weekly activity, the children took the initiative to greet the elderly people. Grandma Chang was delighted when she mentioned that the children greeted them enthusiastically. Grandma Lee was extremely happy that the children loved to attend her activity.

Not big change at all, just felt it wasn't what I expected...the time passed by quickly. When I was with them, I felt... when they greeted us, I felt... they were so sweet. You felt you're welcome (H-1-9).

That made me...didn't think so...l experienced something unexpected, so enthusiastic, they kept asking questions. That's it. I really felt like learning something, so...anyway I was so happy... really surprised 
INTERNATIONAL JOURNAL OF ACADEMIC RESEARCH IN BUSINESS AND SOCIAL SCIENCES

Vol. 10, No. 2, Feb, 2020, E-ISSN: 2222-6990 @ 2020 HRMARS

they were so enthusiastic (E-1-18).

This study found that the children's feedback has resulted in elderly people's positive attitude, which conformed to Mendis' research results. Mendis (1993) studied the changes of two aspects exhibited by the elderly people who took part in intergenerational programs, namely, (1) The social distance between elderly people and children decreased, and (2) Elderly people improved their self-esteem, control and satisfaction with life.

3. Integrating the past and cherishing the present

Elderly people have reached the "integrity vs despair stage" introduced by Erik $\mathrm{H}$. Erikson. In the very last stage of their life, elderly people are faced with an urgent need to reflect on and integrate their memories. By taking part in intergenerational activities, elderly people can reflect on their life experience including their childhood memory, working experience and the affections with family members.

One day, I didn't know what happened. Suddenly, a traditional artistry came across my mind. I immediately thought of this - string figure. I played this with my little sister long time ago. The fine memory long time ago... we made beanbags. That's why...it was pretty good to me, reminding me of the childhood memory... wonderful memory (E-1-22).

I could get along with them. I was trying to figure out if those kids I taught were different from the kids before (F-1-18).

\section{Sense of direction}

Sense of direction refers to the goal of life and the future plan. After taking part in intergenerational program, elderly people said they felt a sense of direction, including the follows:

1. An enhanced focus of life

All elderly people had created a schedule for themselves after they retired. Then, they agreed to participate in the intergenerational program and adjusted their schedule for this program. They did their best to prepare their lectures, treating the lectures as an important task in their life.

I was very happy because it was a wonderful opportunity for me. In the beginning, however, it wasn't easy for me. Nevertheless, I had to do it for 8 weeks and I had to live up to my words. After all, I made it each and every week - eight weeks in total. This is what I promised myself (B-1-12).

Of course I made it each and every week. There was no doubt about it. On this particular day each week, this is the only task for me and I wouldn't do anything else. I had to be there on time. This is the way I am. I always prepared myself in advance for my lecture (F-1-15).

2. Satisfying the need of helping others and learning

All elderly research objects said they had made up their mind to get their jobs done before they joined this program. By taking part in the intergenerational program, elderly people had an opportunity to materialize their dream. Most importantly, they were happy when they helped 
INTERNATIONAL JOURNAL OF ACADEMIC RESEARCH IN BUSINESS AND SOCIAL SCIENCES

Vol. 10, No. 2, Feb, 2020, E-ISSN: 2222-6990 ¿ 2020 HRMARS

others.

We all,,ffelt...we were learning by helping others. Both purposes were satisfied and we had a chance to meet coworkers. It was a wonderful opportunity for me. I must cherish it (H-1-16).

Oh, we had a wonderful opportunity to help others, just do it...it's good to help someone else. We enjoyed helping others. We're happy (A-1-45).

If elderly people continue to take part in the programs, they can regain the role that they have lost after retirement. According to the interviews, elderly people have improved the focus of their life after they took part in intergenerational program. By helping the children, elderly people have an opportunity to materialize their dream and return kindness to the society.

III. Sense of fulfillment

Sense of fulfillment refers to the feeling about the present life. Elderly research objects have improved their sense of fulfillment after they complete the intergenerational program. Details are described as follows:

1. Sharing experience with each other and learning from each other

The intergenerational program required elderly people to be present at the preschool weekly, eight weeks in total. Elderly people were required to interact with children in the classroom even though they were not lecturers. Thus, elderly people had the opportunity to watch each other's teachings and learn from each other. By doing so, each and every elderly person have learned something from each other.

Actually, I learned a lot when I was sitting in the classroom. I found all other elderly people were pretty $\operatorname{good}(H-1-1)$.

I really respect other elderly people. As I could see, other elderly people had spent lots of time to prepare for the class. I learned a lot from them (D-1-24).

2. Enriching life and having fun

For most elderly people, taking part in the intergenerational program once a week wasn't much work. For the elderly people who hardly take part in social occasions, however, intergenerational program was a great opportunity to have fun.

I feel my life has been enriched. Time really flied when I stayed with the kids. I was happy, really happy (F-1-64).

Yes, my life has become more interesting than before (F-1-25).

IV. Sense of autonomy

Sense of autonomy means the sense of control over one's life and his current lifestyle. Upon completion of intergenerational program, the elderly research objects expressed their views about 
INTERNATIONAL JOURNAL OF ACADEMIC RESEARCH IN BUSINESS AND SOCIAL SCIENCES

Vol. 10, No. 2, Feb, 2020, E-ISSN: 2222-6990 @ 2020 HRMARS

their sense of autonomy as follows:

1. Having a plan for the life, unlikely to change much

Sense of autonomy means the sense of control over one's current life. During the interviews, most elderly research objects said their sense of autonomy remained about the same. Most elderly research objects had either served as volunteers or taken part in social activities before they took part in the intergenerational program. This is why the intergenerational program was unable to help elderly research objects change their sense of autonomy significantly.

Hmm...I am a lecturer, helping people understand some animals, plants and environments. I've lectured in both categories. This is why I didn't change much. When we talk about these things...I'm kind of...used to it (G-1-7).

Talking about changes, actually I didn't change at all because I still have a busy schedule after I retired. I never stay at home without doing anything (C-1-36).

\section{Limited time and too many restrictions}

This study provided eight intergenerational activities. Elderly people felt the time was too short for them to help the children meaningfully. Secondly, due to the limited time, elderly people were unable to help children sufficiently:

I didn't have enough time. Had I have some more time, I would find someone else to communicate with him (child)(A-1-10).

We spent a little time with them. Had we have some more time, we would like to help them more, just like the elders helping the younger in the family...maybe they could learn how to get along with the elders, too (F-1-8).

In general, elderly people have improved many aspects related to the meaning in life, such as individual value, sense of direction and sense of fulfillment. According to the data acquired from interviews, elderly people had become aware of their ability after they took part in intergenerational program. Moreover, this study has helped elderly people integrate their life experience and contribute their skills to the society. Meanwhile, elderly people have helped others and improved their life by taking part in the intergenerational program.

With limited time, the intergenerational program arranged by this study was unable to provide activities over a long period time. Elderly people found the children's behavioral problems. Due to limited time, however, they were unable to assist the children intensively and the courses weren't designed to identify children's problems, either. Moreover, the elderly people taking part in intergenerational program were retirees with active lifestyle and a high sense of autonomy. Therefore, the elderly people's sense of autonomy was hardly affected by the intergenerational program. 
INTERNATIONAL JOURNAL OF ACADEMIC RESEARCH IN BUSINESS AND SOCIAL SCIENCES Vol. 10, No. 2, Feb, 2020, E-ISSN: 2222-6990 ¿ 2020 HRMARS

\section{Conclusions}

After taking part in intergenerational program, elderly people found the meaning in their life has been enriched.

This study has found that, upon completion of intergenerational program, elderly people were satisfied with their performance as instructors and thus improved their sense of individual value. Elderly people were delighted with children's positive feedback, and at the same time integrated their past and cherished the present moment. The intergenerational program helped elderly people improve their focus of life, provided an opportunity for elderly people to help others and learn something at the same time, and thus enhanced their sense of direction. Moreover, the intergenerational program allowed elderly people to share experience with each other, learn from each other, enrich their life, and have fun.

After taking part in the intergenerational program, elderly people exhibited significant improvement in several aspects of their meaning in life, such as individual value, sense of direction and sense of fulfillment while less improvement of life meaning in their sense of autonomy.

This study found that, after elderly people completed the intergenerational program, they had exhibited significant improvement in several aspects of their meaning in life, such as individual value, sense of direction and sense of fulfillment while less improvement of life meaning in their sense of autonomy. According to social concepts, the sense of autonomy means the viewpoints about life and death, which have much to do with culture and religious belief. The elderly people taking part in the intergenerational program has enthusiastically participated in the related social affairs over the past years. This is why the short-term intergenerational program was unable to change their sense of autonomy, and therefore elderly people hardly exhibited any change about their sense of autonomy.

\section{Acknowledgement}

My thanks to all elderly people and children who contributed to this study. It would not have been possible without their help. I also like to thanks the reviewers and the editor for their comments.

\section{Corresponding Author}

Meng-Chieh Chao, Ching Kuo Institute of Management and Health/Department of early childhood Educare,Taiwan. Email: shchao@ems.cku.edu.tw

\section{References}

Baum, S. K. (1988). Sources of meaning through the lifespan .Paper presented at the Annual Meeting of the American Psychological Association. Atlanta, GA.

Ekstrom, C. D., Ingman, S. R., \& Benjamin, T. (1999). Gerontology environmental links in aging education toward an intergenerational view of sustainability. Educational Gerontology, 25, 613621.

Hatton-Yeo, A., \& Ohsako, A. (2000) Intergenerational programmes: Public policy and research implications an international perspective. Retrieved Jan 12, 2019, from https://cdn.uclouvain.be/public/Exports\%20reddot/aisblgenerations/documents/DocPart_Etud_UnescoPublicPolicy.pdf 
INTERNATIONAL JOURNAL OF ACADEMIC RESEARCH IN BUSINESS AND SOCIAL SCIENCES

Vol. 10, No. 2, Feb, 2020, E-ISSN: 2222-6990 @ 2020 HRMARS

Kaplan, M. S. (2001). School-based intergenerational programs. ,Retrieved Jan 12, 2019 ,from https://unesdoc.unesco.org/ark:/48223/pf0000200481

Krause, N. (2007). Longitudinal study of social support and meaning in life. Psychology and Aging,22(3), 456-469

LinOu, G.Y. (2000). The effects of an intergenerational program on life satisfaction of nursing home residents in Northern Colorado,Unpublished doctoral dissertation, University of Northern Colorado.

Mendis, K. P. (1993). The effects of participation in an intergenerational program on the psychological well-being of the elderly. Unpublished doctoral dissertation, Fordham University.

Moore, S. L., Metcalf, B., \& Schow, E. (2000). Aging and meaning in life : Examining the concept. Geriatric Nursing,21(1), 27-29

Reitzes, D. C., \& Mutran, E. J. (1994). Middle aged working men and women. Research on Aging, 16(4), 355

Reker, G. T. (1997). Personal meaning, optimism, and choice: Existential predictors of depression in community and institutional elderly. The Gerontologist,37(6), 709-716.

Wenzel, M. P. S., \& Sorensen, S. (2000). Changes in attitudes among children and elderly adults in intergenerational group work. Educational Gerontology,26(6), 523-540. 